\title{
Viewpoint
}

\section{Women with COPD}

For decades, there has been gender imbalance when talking about different medical conditions. One key factor is that the "typical patient" has often been presented as male in descriptions and associated imagery. These thoughts regarding the "textbook patient" or the "typical medical case" are what creates health discrepancies and a dismissive attitude to other groups of individuals. Men and women should be equally represented in medical literature, medical artwork, clinical trials, etc. to allow for equal representation of both genders across all platforms. Creating a definition of a patient that all genders can relate to regarding their health is extremely important for the patient's own engagement with their health.

In 2020, COPD remains a substantial cause of morbidity and mortality worldwide, creating a significant burden on the quality of life of people living with the condition and their families, social aspects of life and an increasing burden on the healthcare system. In Canada, for example, COPD is the fourth most common cause of hospitalisation in men and the sixth most common cause in women [1]. In 2019, 850000 Canadians over the age of 35 years reported a diagnosis of COPD [2]. In the past, COPD has been thought of as a predominately male-dominated condition, an opinion that is immensely outdated, with a lack of awareness for women developing COPD. In women, the prevalence and mortality of COPD has significantly increased with figures suggesting a two-fold increase over the past 20 years [3].
However, the incidence of men with COPD has stabilised [3]. A cross-sectional study published in the International Journal of Chronic Obstructive Pulmonary Disease, from Spain, looked at the gender differences in COPD by identifying numerous clinical characteristics of the female participants. Of the 1610 participants recruited in the study, $17.9 \%$ were women. The study highlighted a significant difference between genders regarding the patient's smoking status, with higher numbers of men reported as current smokers and ex-smokers and more women with COPD who had never smoked (9.1\% in comparison to the male participants reported at $0.6 \%$ [4]). It has further been suggested that women are more susceptible to the effects of tobacco smoke, and there is evidence that exposure to environmental tobacco smoke is associated with COPD and affects women more often than men. Biomass smoke exposure has been associated with COPD in rural and urban women [5].

In regard to the diagnosis of COPD, the time taken to diagnose a woman is often longer in comparison to a man with COPD and subsequently women are often identified at a later stage within the disease process. This poses difficulties in providing optimal early treatment and improving a patient's quality of life symptomatically. A delay in diagnosis can lead to increased anxiety for the patient and disengagement with their own health. Also, many women are unaware of the key symptoms of COPD, resulting in a failure to report their symptoms to their primary care physician [6].

@ERSpublications

Health inequalities regarding gender are extremely prevalent, and specifically in conditions such as COPD. No woman should ever be dismissed in regard to their health and underlying medical history. https://bit.ly/2X7Klmd

Cite as: Mclvor ER, Saraiva I, Denning J, et al. Women with COPD. Breathe 2020; 16 : 200239. 
In an abstract presented at the 2019 American Thoracic Society (ATS) International Conference, data was presented showing that women with COPD had smoked fewer cigarettes in comparison to men. However, women with COPD experienced more severe symptoms, a poorer quality of life, and reported more severe acute exacerbations then men. The SPIROMICS prospective cohort study [7], investigated the differences in COPD outcomes in relation to gender. The study included baseline data from 1832 participants with a formal diagnosis of COPD and $>20$ pack-years of cigarette smoking reported. Of the total participants, $42 \%$ were woman. Researchers looked at numerous different clinical markers to assess the degree of COPD morbidity, including the COPD assessment test, the 6-min walk test (6MWT) with reported distance, symptom scores from the modified Medical Research Council questionnaire and respiratoryspecific quality of life measures from the St George's Respiratory Questionnaire (SGRQ). The study used a regression-based model to identify the association between gender and COPD morbidity. Results stated that, within the female subgroup, there was a greater level of impairment regarding quality of life with the SGRQ (females scored 4.48 higher than males) and shorter reported distances on the 6MWT (women $31.4 \mathrm{~m}$ less in comparison to the male participants). Women had higher chances of hypoxaemia during the $6 \mathrm{MWT}$ and reported an increase in the frequency and severity of COPD exacerbations in comparison to the male participants. Evidently, the study highlights the severity and impairment in a women's quality of life whilst living with COPD, with reduced exercise tolerance and increased acute exacerbations in comparison to the male participants.
Trends in COPD hospitalisations identified that within the USA the number of deaths in hospitals related to COPD has declined [8]. However, despite this overall decline, woman account for a higher proportion of hospitalisations and inpatient deaths. The study looked at the trends regarding COPD hospitalisations over the course of 2005 to 2014 via retrospective analysis. The researchers used an International Classification of Diseases Ninth Revision (ICD-9) algorithm to identify hospitalisations with a primary discharge diagnosis of COPD. The results of the study identified that each year, from 2005 to 2014, women accounted for the higher proportion of hospitalisations and inpatient deaths when directly compared to men. The study noted that, on average, women were slightly younger than the males at the time of admission; however, women reported a reduced impairment of function in relation to the men. The study evidently highlights the gender discrepancies experienced by the higher proportion of women requiring hospitalisation and ultimately the number of inpatient deaths. However, the true scope of COPD among women may still be vastly underestimated due to the lack of formal diagnosis with spirometry in women and dismissive attitudes towards women regarding what the "typical symptoms" are, or whether or not their smoking history is "significant".

In order to address some of the issues discussed in this viewpoint, the authors approached the European Respiratory Society (ERS) and European Lung Foundation (ELF) to develop an art competition to better depict women who have COPD. To run this competition, ELF gathered testimonies, images and videos from women with COPD to provide
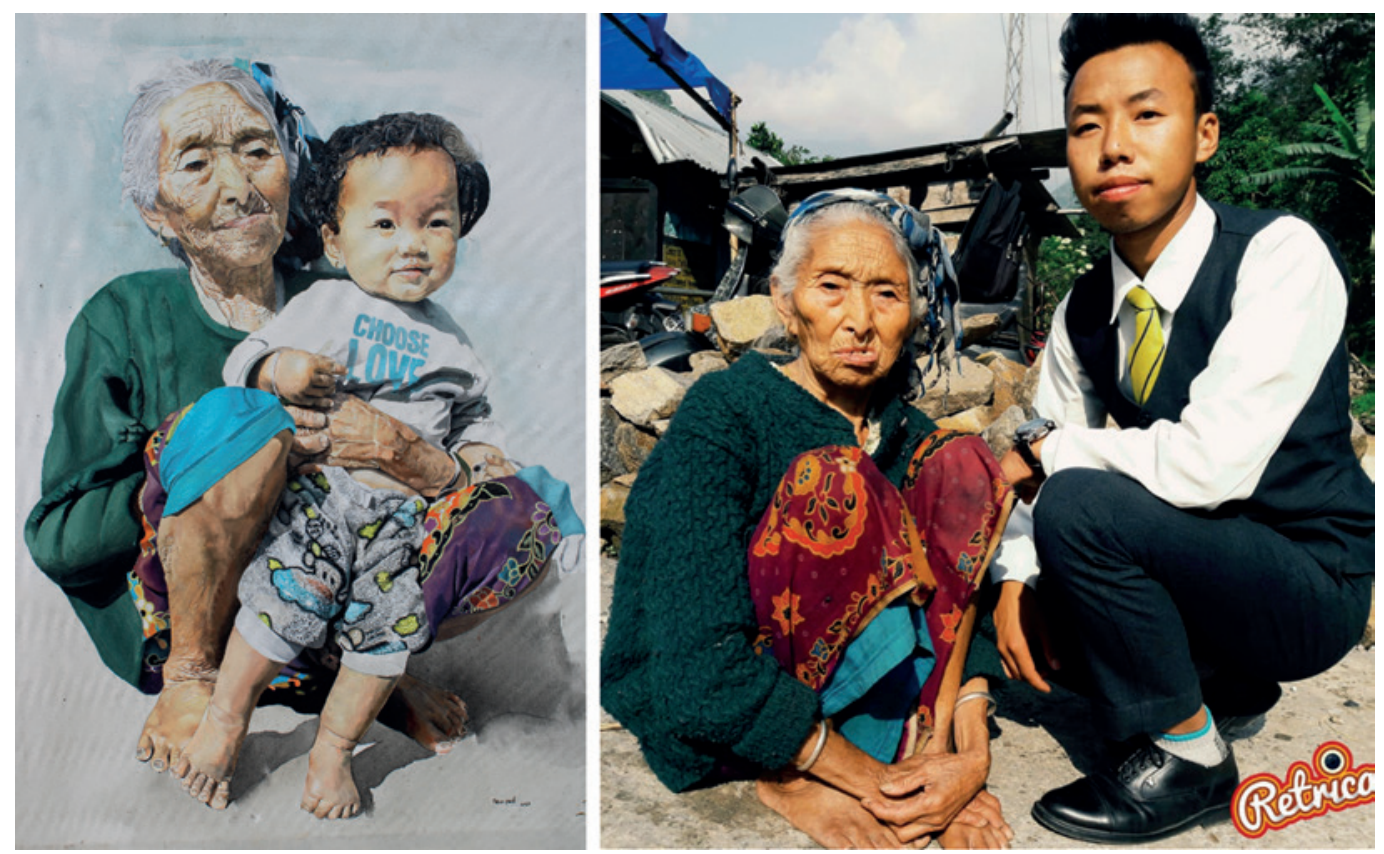

Figure 1 The winning piece of art. My Grandma painted by Deo Prasad Rai (left) and a photo of Deo Prasad Rai and his grandmother (right). 
insight into the female experience of this disease. The contest was then promoted via many routes (website, newsletters, social media) and artists were asked to create one piece of art, using any medium, to portray how women experience COPD.
A total of 57 pieces of artwork were submitted and judged by an expert panel of women with COPD, healthcare professionals and professional artists, and the judges selected their top five submissions. These five images were shared online
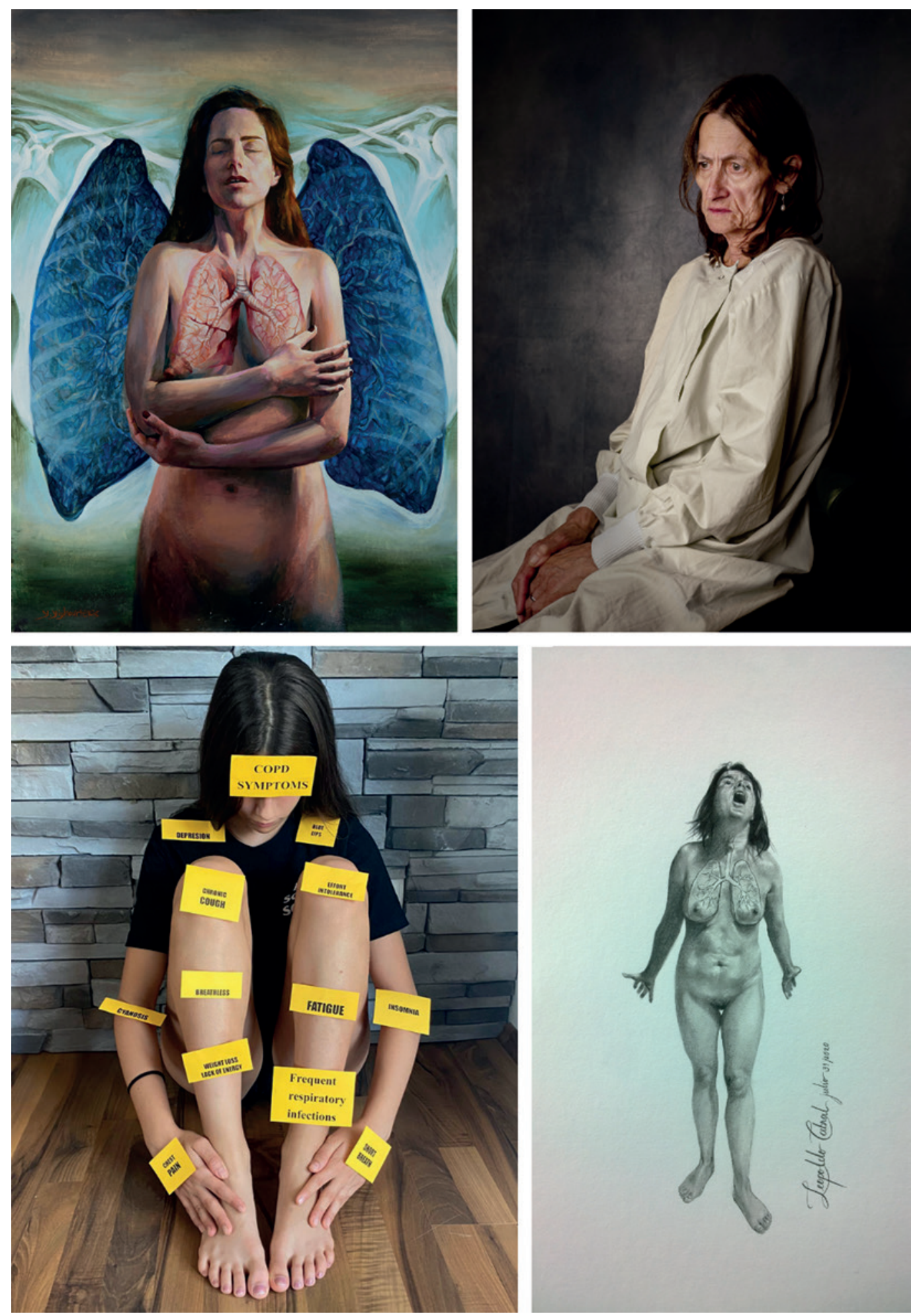

Figure 2 The four second-place submissions. Breathe by Yannis Yighourtakis, Athens, Greece (top left). Ayspnea by llir Tsouko, Berlin, Germany (top right). COPD life by Zdenka Bradač, Zagreb, Croatia (bottom left). Breathe by Leopoldo Cabral, Bogotá, Colombia (bottom right). 
during the Virtual ERS International Congress 2020, and Congress delegates, patients and the public were asked to vote for their favourite. Over 7000 votes were cast using woobox.com. The winning piece of art is shown in figure 1. "My Grandma" was painted by Deo Prasad Rai from Sikkim, India. The artwork represents the artist's grandma, 74-year-old Chandra Maya, who has been suffering from shortness of breath and chronic cough as a result of her COPD for many years. She was a long-term smoker, but while playing with her grandchild Ningwa she avoided smoking so that she did not put Ningwa at an increased risk of developing COPD in later life. The grandma's unwell face in the painting portrays the suffering of women with COPD.

The other four shortlisted of pieces of art are shown in figure 2. The winner of the competition will receive a EUR 5000 commission to create a series of images of women with respiratory disease, which will be unveiled on International Women's Day 2021.

Isabel Saraiva, who is a former chair of ELF and a woman with COPD, has made it a priority to improve the representation of women with respiratory disease. She feels that: "This competition is a tribute to all women who are often forgotten in their specific medical conditions, respiratory or otherwise."

It is hoped that the competition will help promote women's health and the underrepresentation of women in medical artwork. Health inequalities regarding gender are extremely prevalent, and specifically in conditions such as COPD. No woman should ever be dismissed in regard to their health and underlying medical history. The art competition for Women with COPD is a tribute to all women with underlying medical conditions.

\section{Affiliations}

Emma R. Mclvor ${ }^{1}$, Isabel Saraiva ${ }^{2}$, Jessica Denning ${ }^{2}$, R. Andrew Mclvor ${ }^{3}$

${ }^{1}$ Queen's University Belfast School of Medicine, Dentistry and Biomedical Sciences, Belfast, UK. 2European Lung Foundation, Sheffield, UK. ${ }^{3}$ Faculty of Health Sciences, McMaster University, Hamilton, ON, Canada.

\section{Acknowledgements}

We would like to thank the European Respiratory Society (ERS) and European Lung Foundation (ELF) for their support. We would also like to thank the judging panel consisting of: Elaine Philpot Bruce (a woman living with COPD); Samira Addo, Sara Lavelle and Colin Davidson (Portrait artists); and Tobias Welte (respirologist and ERS representative).

The Prize of EUR 5000 will be awarded by Mclvor Medical Professional Corporation.

\section{Conflict of interest}

E. Mclvor has nothing to disclose. I. Saraiva was the Chair of the European Lung Foundation at the time of this competition. J. Denning is an employee of the European Lung Foundation. R.A. Mclvor has nothing to disclose.

\section{References}

1. Health Canada. Chronic Obstructive Pulmonary Disease (COPD) in Canada. Date last updated:1 May 2018. https://healthinfobase.canada.ca/datalab/copd-blog.html.

2. Statistics Canada. Table 13-10-0096-19 Chronic obstructive pulmonary disease (COPD), 35 years and over. https://doi org/10.25318/1310009601-eng

3. Mannino DM, Gagnon RC, Petty TL, et al. Obstructive lung disease and low lung function in adults in the United States: data from the National Health and Nutrition Examination Survey, 1988-1994. Arch Intern Med 2000 160: 1683-1689.

4. Trigueros JA, Riesco JA, Alcázar-Navarrete B, et al. Clinical features of women with COPD: sex differences in a crosssectional study in Spain ("The ESPIRAL-ES Study"). Int J Chron Obstruct Pulmon Dis 2019; 14: 2469-2478.
5. Sana A, Somda SMA, Meda N, et al. Chronic obstructive pulmonary disease associated with biomass fuel use in women: a systematic review and meta-analysis. BMJ Open Respir Res 2018; 5: e000246.

6. Tsiligianni I, Román Rodríguez M, Lisspers K, et al. Call to action: improving care for women with COPD. Prim Care Respir Med 2017; 27: 11.

7. Lambert A, Dieter B, Barjaktarevic I, et al. Women with COPD experience increased symptom burden, frequent and severe exacerbation, and impaired functional capacity as compared to men in SPIROMICS. Am J Respir Crit Care Med 2019; 199: A5941.

8. Goel K, Bailey M, Borgstrom M, et al. Trends in chronic obstructive pulmonary disease hospitalization and in-hospital deaths in the United States by sex: 2005 to 2014. Ann Am Thorac Soc 2019; 16: 391-393. 